\title{
New VMD2 gene mutations identified in patients affected by Best vitelliform macular dystrophy
}

\section{Marchant, K Yu, K Bigot, O Roche, A Germain, D Bonneau, V Drouin-Garraud, D F Schorderet, F Munier, D Schmidt, $P$ Le Neindre, C Marsac, M Menasche, J L Dufier, R Fischmeister, C Hartzell, M Abitbol}

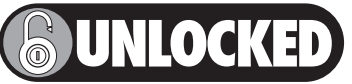

This paper is freely available online under the BMJ Journals unlocked scheme, see http:// jmg.bmi.com/info/unlocked.dtl

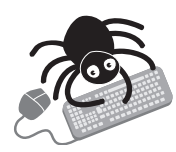

J Med Genet 2007;44:e70 (http://www.jmedgenet.com/cgi/content/full/44/3/e70). doi: 10.1136/jmg.2006.04451 1

Supplementary data files are available at $\mathrm{http}: / /$ jmg.bmj.com/supplemental

See end of article for authors' affiliations

.....................

Correspondence to: Dr M Abitbol, Centre de recherche thérapeutique en ophtalmologie, Université René Descartes Paris V, Faculté de Médecine Necker-Enfants Malades, 156 rue de Vaugirard, 75015 Paris, France; abitbol@necker.fr Dr C Hartzell, Department of Cell Biology, Emory University School of Medicine, 615 Michael St, Atlanta, GA 30322, USA; criss.hartzell@emory.edu

Received 5 June 2006 Revised 10 August 2006 Accepted 17 August 2006

\begin{abstract}
Purpose: The mutations responsible for Best vitelliform macular dystrophy (BVMD) are found in a gene called VMD2. The VMD2 gene encodes a transmembrane protein named bestrophin-1 (hBestl) which is a $\mathrm{Ca}^{2+}$. sensitive chloride channel. This study was performed to identify disease-specific mutations in 27 patients with BVMD. Because this disease is characterised by an alteration in $\mathrm{Cl}^{-}$channel function, patch clamp analysis was used to test the hypothesis that one of the VMD2 mutated variants causes the disease.

Methods: Direct sequencing analysis of the 11 VMD2 exons was performed to detect new abnormal sequences. The mutant of hBestl was expressed in HEK-293 cells and the associated $\mathrm{Cl}^{-}$current was examined using whole-cell patch clamp analysis.

Results: Six new VMD2 mutations were identified, located exclusively in exons four, six and eight. One of these mutations (Q293H) was particularly severe. Patch clamp analysis of human embryonic kidney cells expressing the Q293H mutant showed that this mutant channel is non-functional. Furthermore, the Q293H mutant inhibited the function of wild-type bestrophin-1 channels in a dominant negative manner.

Conclusions: This study provides further support for the idea that mutations in VMD2 are a necessary factor for Best disease. However, because variable expressivity of VMD2 was observed in a family with the Q293H mutation, it is also clear that a disease-linked mutation in VMD2 is not sufficient to produce BVMD. The finding that the Q293H mutant does not form functional channels in the membrane could be explained either by disruption of channel conductance or gating mechanisms or by improper trafficking of the protein to the plasma membrane.
\end{abstract}

$\mathrm{B}$ est disease, also called Best vitelliform macular dystrophy (BVMD), is a bilateral, progressive disease of the retinal pigment epithelium (RPE) leading to decreased visual acuity. Best disease has an autosomally dominant transmission, but the penetrance is incomplete and its expression is highly variable. ${ }^{1-3}$ Although Best disease is the second most common form of juvenile macular degeneration, with an onset usually before 15 years of age, only about $1 \%$ of all cases of macular degeneration can be attributed to Best disease. ${ }^{4}$ However, the degree of central vision impairment and the age of onset of symptoms varies widely, ${ }^{5-7}$ even among members of the same family.

On fundus examination, the central macula has a transient "egg yolk"-like appearance measuring between one and two disc areas in size. During angiographic examination, a blockade of the choroidal fluorescence by vitelliform material was observed. ${ }^{8}$ This means the lesion is an abnormal accumulation of lipofuscin-like material in front of the choroid and within and beneath the RPE, but not within the neural retina. At the vitelliform stage, visual acuity is surprisingly good or slightly subnormal. The lesion evolves through several stages over many years (scrambled egg stage, cyst stage, pseudohypopyon stage, atrophic stage, see classification by Mohler and Fine ${ }^{9}$ ), with visual acuity usually decreasing when disintegration of the yellowish material has been observed (scrambled egg stage). ${ }^{8}$ When atrophic changes take place, visual acuity may drastically be reduced. Infrequently, in some patients, the lesion may degenerate, resulting in the development of subretinal haemorrhage with identifiable or unidentifiable choroidal neovascular membranes. ${ }^{10-13}$ Some people without any subretinal macular deposit but who carry causative BVMD mutations may never experience a noticeable decline of central vision.

About $10 \%$ of affected eyes have multifocal lesions in the extrafoveal region. Furthermore, lesions similar to those seen in Best disease may occur in patients with adult vitelliform macular dystrophy (AVMD). ${ }^{14}{ }^{15}$ In some cases, similar conditions are caused by mutations of other genes, such as the peripherin/RDS gene. ${ }^{16}$

Abbreviations: $A V M D$, adult vitelliform macular dystrophy; BVMD, Best vitelliform macular dystrophy; EOG, electrooculogram; HEK, human embryonic kidney; mfERG, multifocal electroretinography; OCT, optical coherence tomography; RPE, retinal pigment epithelium 
The differential diagnosis of BVMD from other macular dystrophies is most effectively made by measuring the electrooculogram (EOG), ${ }^{17}{ }^{18}$ whereas full-field electroretinograms are usually normal in patients with BVMD. ${ }^{1}$ Although for years the EOG has been considered as the main functional test to define BVMD and was used especially for the detection of non-manifesting carriers of the mutated VMD2 gene, recent studies have reported normal EOG recordings in patients with BVMD. ${ }^{6719}$ Thus, it seems that a normal EOG alone may not unequivocally exclude non-manifesting carriers. A complete clinical examination of patients combined with molecular genetics studies of the VMD2 gene is mandatory for adequate counselling of the families. In both affected patients and carrier patients, EOG often shows an abnormal light-peak/dark-trough ratio. Abnormal EOG responses can be recorded in asymptomatic patients, sometimes long before the appearance of any clinical manifestations. Multifocal electroretinography (mfERG) shows variable central function loss depending on the stage of the disease and has become an important tool in assessing the function of the remaining macular cones. ${ }^{2021}$

The mutations responsible for Best disease are found in a gene called $V M D 2$. It encodes a transmembrane protein named bestrophin-1 (hBestl). The protein is located in the basolateral plasma membrane of RPE cells. ${ }^{22}$ Bestrophin is a member of the RFP-TM family of proteins, so named for their highly conserved arginine, phenylalanine, proline (RFP) motif. ${ }^{23-25}$ Bestrophin contains several domains that are highly conserved between species. ${ }^{23}$ Patch clamp studies of bestrophin and other RFP-TM family members heterologously overexpressed in cell culture have suggested that bestrophin is a $\mathrm{Ca}^{2+}$-sensitive chloride channel. ${ }^{26-28}$

Some mutations in the VMD2 gene have also been associated with some cases of bull's-eye maculopathy ${ }^{29}$ and of AVMD..$^{29-32}$

In this study, we identify six new, independent, diseasespecific mutations in patients with BVMD and their families, and in isolated patients. One of these mutations (Q293H) found in a large family from the west part of France is particularly severe. Patch clamp analysis of human embryonic (HEK) cells expressing the Q293H mutant bestrophin-l shows that this mutant channel is non-functional. Furthermore, the Q293H mutant inhibits the function of wild-type bestrophin-1 channels in a dominant negative manner. These findings support the idea that BVMD is a chloride channelopathy.

\section{PATIENTS AND METHODS \\ Patients}

Blood samples were collected from patients after informed consent was signed by the adults or by both parents of each child involved in the study, according to the Bioethics Laws of European Union and France and according to the Guidelines of the Helsinki Declaration. Of the 27 patients with BVMD, 25 were from France (19 cases in families B-I and six isolated patients (A-F)) and two were from the French-speaking part of Switzerland (families A and J; table 1). The control group consisted of 100 unrelated individuals from France who were unaffected by any form of macular degeneration or inherited retinal dystrophy and who had no family history of BVMD (as described by Marchant $e t a l^{33}$ ).

\section{Clinical diagnosis of Best disease}

The clinical diagnosis of Best disease was based on one or multiple subfoveal vitelliform lesions in at least one eye. At least one affected individual from each family was diagnosed by both EOG (Metrovision, Pérenchies, France) and fundus examination. Visual acuity was evaluated using a Snellen chart. In addition, families B, C and I were also evaluated by mfERG (Metrovision) and optical coherence tomography (OCT)

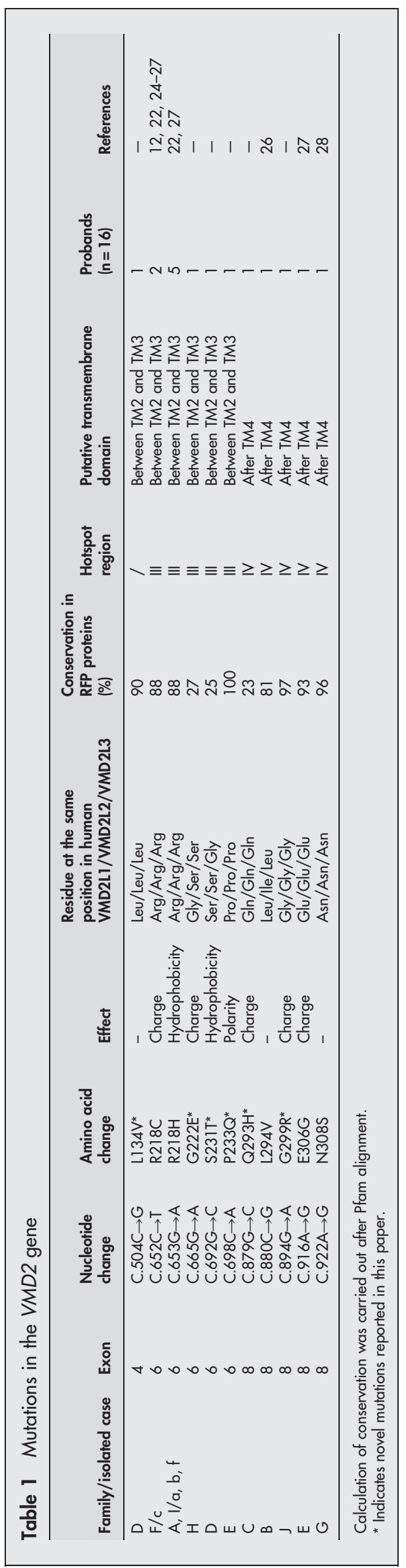


analysis (Stratus OCT 3000, Carl Zeiss). EOG and mfERG recordings were performed according to the International Society for Clinical Electrophysiology of Vision standard protocol.

\section{VMD2 gene analysis}

Genomic DNA was extracted from all study participants from venous blood using a standard proteinase K extraction protocol. The VMD2 gene consists of 11 exons (NM 004183). Each exon with a short flanking intronic sequence at both the $5^{\prime}$ and $3^{\prime}$ ends was amplified from all affected BVMD cases and unaffected family members (79 patients) and 100 controls using touch-down PCR with oligonucleotide primers designed to an intronic sequence flanking the exon (the sequences of the primers used and PCR cycling conditions are available on request from the authors). DNA was then bidirectionally sequenced using an automated sequencer and dye-terminator chemistry (ABI Prism DNA 310 machine).

\section{Functional analysis of variant in HEK cells} Site-specific mutagenesis of hBestl and heterologous expression in mammalian cell lines

Point mutations were made in hBestl using a PCR-based sitedirected mutagenesis kit (Quickchange; Stratagene), as previously described. ${ }^{34}$ Wild-type hBestl cDNA in pRK5 was provided by Dr Jeremy Nathans (Johns Hopkins University). HEK-293 cells (human embryonic kidney, ATCC) were cotransfected with hBestl cDNA and a vector expressing EGFP (pEGFP; Invitrogen) using Fugene-6 transfection reagent (Roche Applied Science, Indianapolis, Indiana, USA). We transfected the cells of one $35 \mathrm{~mm}$ culture dish with $1 \mu \mathrm{g}$ hBestl cDNA to obtain a modest $\mathrm{Ca}^{2+}$-activated $\mathrm{Cl}^{-}$current ( 1 to $2 \mathrm{nA}$ per cell). One day after transfection, cells were dissociated and replated on glass coverslips for electrophysiological recording. Transfected cells were identified by EGFP fluorescence and used for patch clamp experiments within 3 days of transfection.
Electrophysiology

Whole-cell patch clamp recording was conducted essentially as described by Qu et al. ${ }^{34}$ Briefly, patch pipettes (2-3.5 $\mathrm{M} \Omega$ filled with the standard intracellular solution) were made of borosilicate glass (Sutter Instrument Co., Novato, California, USA), pulled by a Sutter P-2000 puller (Sutter Instrument Co.), and fire polished. The bath was grounded via a $3 \mathrm{M} \mathrm{KCl}$ agar bridge connected to a $\mathrm{Ag} / \mathrm{AgCl}$ reference electrode. Solution changes were performed by perfusing the $1 \mathrm{ml}$ chamber at a speed of about $4 \mathrm{ml} / \mathrm{min}$. Data were acquired by an Axopatch 200A amplifier controlled by Clampex 8.1 via a Digidata 1322A data acquisition system (Axon Instruments Molecular Devices, Sunnyvale, California, USA). Experiments were conducted at room temperature $\left(20-24^{\circ} \mathrm{C}\right)$. The standard pipette solution contained (in mM) $146 \mathrm{CsCl}, 2 \mathrm{MgCl}_{2}, 5\left(\mathrm{Ca}^{2+}\right)$-EGTA, 8 HEPES, 10 sucrose, $\mathrm{pH} 7.3$, adjusted with NMDG. The free $\left[\mathrm{Ca}^{2+}\right]$ in the high $\mathrm{Ca}^{2+}$ solution was about $5 \mu \mathrm{M}$. The standard extracellular solution contained (in $\mathrm{mM}$ ) $140 \mathrm{NaCl}, 5 \mathrm{KCl}, 2$ $\mathrm{CaCl}_{2}, 1 \mathrm{MgCl}_{2}, 15$ glucose, 10 HEPES, pH 7.3 with $\mathrm{NaOH}$. This combination of solutions set the reversal potential $\left(\mathrm{E}_{\mathrm{rev}}\right)$ for $\mathrm{Cl}^{-}$ currents to zero, whereas cation currents carried by $\mathrm{Na}^{+}$or $\mathrm{Cs}^{+}$ have very positive or negative $\mathrm{E}_{\mathrm{rev}}$, respectively.

\section{RESULTS AND DISCUSSION}

Most of the patients affected with BVMD included in our study presented a classical BVMD phenotype with bilateral "egg yolk"-like deposits observed funduscopically (supplementary data file 1 , available at http://jmg.bmj.com/supplemental), with a significant bilateral decrease of the Arden ratio on EOG examination $(R \leqslant 1.3)$. In some patients presenting an abnormal lamination of the retina or a considerable decrease of retinal thickness, OCT analysis displayed an alteration of the structure of the neurosensory retina (supplementary data file 2 , available at http://jmg.bmj.com/supplemental). In addition, when the mfERG was performed in affected patients, alterations were almost always observed (supplementary data file 3 , available at http://jmg.bmj.com/supplemental). Family C (fig 1)

A

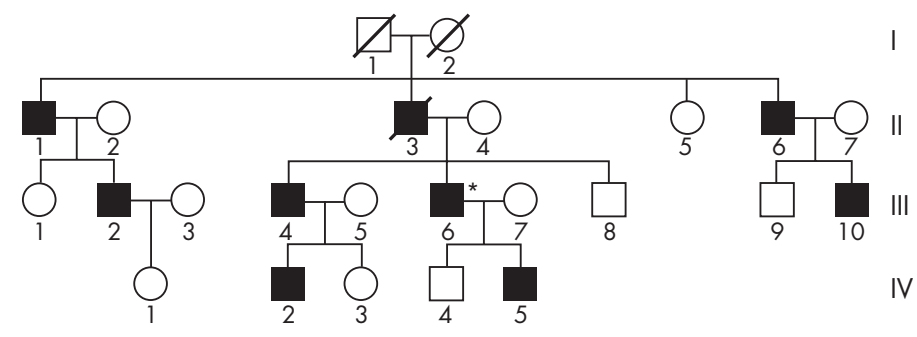

B

\begin{tabular}{|c|c|c|c|c|c|c|c|c|}
\hline Patients & $\begin{array}{c}\text { Age of } \\
\text { onset } \\
\text { (years) }\end{array}$ & $\begin{array}{c}\text { Age at } \\
\text { examination } \\
\text { (years) }\end{array}$ & $\begin{array}{l}\text { Visual } \\
\text { acuity }\end{array}$ & $\begin{array}{c}E O G \\
\text { (Arden ratio) } \\
n>1.8\end{array}$ & Fundus examination & Fluorescein angiography & mFERG & OCT \\
\hline$\| 1$ & $<6$ & 71 & $<20 / 100$ & 1.3 & $\begin{array}{l}\text { Bilateral arrophy of the } \\
\text { central macula }\end{array}$ & $\begin{array}{l}\text { Choroidal neovessel } \\
\text { development very extensive } \\
\text { in the right eye }\end{array}$ & $\begin{array}{l}\text { Retinal electrogenesis of the } \\
\text { central cones severely altered }\end{array}$ & $\begin{array}{l}\text { Dramatic thinning of the neurosensory retina } \\
\text { with an epiretinal membrane-like detachment } \\
\text { Enhanced optical reflectivity from the choroid }\end{array}$ \\
\hline 111-2 & 5 & 35 & $20 / 200$ & 1.1 & Typical vitelliform lesions & $\begin{array}{l}\text { Devepopment of foveolar } \\
\text { choroidal neovessels }\end{array}$ & $\begin{array}{l}\text { Retinal electrogenesis of the } \\
\text { central cones altered }\end{array}$ & $\begin{array}{l}\text { Flattened foveal contour } \\
\text { Elevation of the neurosensory retina due to a } \\
\text { mound of highly reflective material at the RPE layer } \\
\text { Disruption of the photoreceptor layer }\end{array}$ \\
\hline $111-6$ & - & 41 & $20 / 20$ & 1 & Normal & Normal & Normal & Normal \\
\hline IV-5 & 5 & 10 & $20 / 200$ & 1 & $\begin{array}{l}\text { Bilateral vitelliform appearance } \\
\text { Rapid fragmentation of the } \\
\text { lesion in the right eye }\end{array}$ & Not done & Not done & $\begin{array}{l}\text { Elevation of the macular retina due to the } \\
\text { vitelliform lesion } \\
\text { Highly reflective material at the RPE layer }\end{array}$ \\
\hline
\end{tabular}

Figure 1 (A) Pedigree of the family C affected by a Q293H mutation in the VMD2 gene causing Best disease. (B) Clinical diagnosis of Best disease of this family. 
presented noticeable exceptions to this phenotype. Nearly all affected individuals in this family were diagnosed at a very early age: about 5 years of age with typical vitelliform lesions already visible in funduscopic examination and EOG alterations (fig 1). Although the phenotype of family $\mathrm{C}$ was especially severe, the general pattern of variable expressivity was seen among different members of this pedigree carrying the same mutation.

\section{Genetic analysis}

For each patient with BVMD, we found only one mutation in the coding sequence of VMD2. Among these mutations, five have previously been reported to be common BVMD mutations, ${ }^{23}{ }^{33}{ }^{35-39}$ but six are novel mutations. All these mutations were missense mutations. They were mainly located in exons four, six and eight. Five of the six new mutations (G222E, S231T, P233Q, Q293H and G299R) are located in regions known to be frequently affected by mutations ("hotspot" regions). None of these changes was found in the 100 controls. Table 1 gives a summary of the mutations. All affected family members in each family shared the same pathogenic mutation. The mutations were absent in the unaffected family members.

According to Bakall's model of hBestl topology, ${ }^{35}$ the new missense L134V mutation found in exon four is located between the second transmembrane (TM2) and the third transmembrane (TM3) putative domain of bestrophin. This mutation does not substantially change the electric charge or the nature of the amino acid, and therefore it is not obvious how this modification leads to BVMD. However, the same type of mutation has been previously described in a patient with BVMD and was considered a pathogenic alteration (L294V). ${ }^{37}$ Leucine is completely conserved at position 134 in the bestrophin-related family members (VMD2L1, VMD2L2 and $V M D 2 L 3)$, suggesting that it plays an important functional or structural role. The Leul34 residue is also highly conserved among other species, including nematodes. ${ }^{23}$ Therefore, this substitution is likely to be a pathogenic mutation.

We found three new missense mutations in exon six (G222E, S231T and P233Q). These amino acids are located between TM2 and TM3. Gly222 is only conserved in human VMD2L1 whereas Ser231 is conserved in VMD2L1 and VMD2L2. The Pro233 residue is invariant within the entire human VMD2-like protein family and within phylogenetically distant bestrophin orthologues.

Two new mutations (Q293H and G299R) are located in exon eight of $V M D 2$, in the fourth defined hotspot region, and after the fourth putative transmembrane (TM4) domain of bestrophin. Gln293 and Gly299 are invariant in human VMD2L1, VMD2L2 and VMD2L3. ${ }^{25}$ Gly299 is also highly conserved within RFP family members. The Q293H mutation cosegregated with the disease in all the members of family $\mathrm{C}$ who had symptoms of Best disease and none of the asymptomatic members of family C carried the Q293H mutation (patient III-6, fig 1). The Q293H mutation, however, exhibited a variable expressivity because patient III-6 had an extinguished EOG but normal visual acuity and normal funduscopic examination (supplementary data file 4, available at http://jmg.bmj.com/supplemental). It may be that the age of onset of the clinical manifestations in this family is variable, as suggested in recent studies ${ }^{5-7}$ It may also be that a high level of expression of the wild-type allele may compensate for the mutant allele, as suggested by McGee et a ${ }^{40}$ to explain reduced penetrance and variable expressivity in retinitis pigmentosa. There may be variable regulatory regions within the $V M D 2$ promoter sequence that modulate the level of expression of the wild-type allele relative to the mutant allele. Esumi et $a l^{41}$ have identified two positive regulatory regions in the VMD2 promoter sequence, from -585 to $-541 \mathrm{bp}$ for high-level expression and from -56 to $-42 \mathrm{bp}$ for low-level expression. They also suggested that E-box binding factors such as microphthalmia-associated transcription factor may act as positive regulators of VMD2 expression. Therefore, we cannot exclude a nucleotide change, possibly corresponding to a single-nucleotide polymorphism in the promoter sequence, as causing the incomplete penetrance and the variability of VMD2 expression between the asymptomatic patient (III-6) and the BVMD affected patients in family C. Another possibility is that polymorphisms in the wild-type allele compensate for the defect in the mutant allele. Such an allelic effect was suggested for the non-penetrance of mutations at the $R P I I$ locus. Vithana et $a l^{42}$ showed that asymptomatic patients with autosomal dominant retinitis pigmentosa (RP11) inherit a different wild-type allele of the PRPF3I gene than that inherited by patients with symptoms.

Functional analysis of the Q293H variant in HEK cells Sun $e a^{26}$ have previously shown that certain hBestl mutations induce smaller whole-cell currents than wild-type hBestl when expressed in HEK-293 cells. Three of the mutations they studied occur at the same positions as three of the mutations we have identified (R218S, Q293K and G299E), but the substituted amino acid is different (R218C/H, Q293H and G299R). They found that the amplitude of the current induced by the Q293K mutation was less than 25\% that of the wild-type current.

To test the hypothesis that the Q293H mutation produces Best disease because it alters $\mathrm{Cl}^{-}$channel function, we expressed the Q293H mutant of hBestl in HEK-293 cells and examined associated $\mathrm{Cl}^{-}$current using whole-cell patch clamp anlaysis. ${ }^{28} 34{ }^{43}{ }^{44}$ Figure 2A shows the $\mathrm{Cl}^{-}$currents in HEK-293 cells associated with expression of hBestl wild-type cDNA as we have previously reported..$^{34}$ The currents are time and voltage independent. The current-voltage relationship is essentially linear (fig 2D). Figure 2B shows the currents produced by the Q293H mutation. The currents are extremely small and cannot be clearly differentiated from the endogenous $\mathrm{Cl}^{-}$currents in HEK-293 cells. The Q293H mutation is essentially non-functional. This may be consistent with the severe phenotype of family C. Some bestrophin mutations have been shown to behave as dominant negatives: coexpression of the mutant bestrophin with the wild-type causes a reduction or elimination of the wild-type current. ${ }^{27}{ }^{28}$ Because disease is inherited in a dominant manner with the Q293H mutation, one might expect that this mutation is also a dominant negative. To test this possibility, the Q293H mutant was coexpressed with wild-type hBest 1 . The currents obtained from cells coexpressing wild-type and Q293H hBestl had currents that were reduced significantly in amplitude to those cells expressing hBestl wildtype alone (fig 2C,E). On average, the current amplitude with wild-type and Q293H expressed together was less than half that of the wild-type alone. Thus, Q293H has a dominant negative effect. The reason why the Q293H mutation does not completely abolish the wild-type current could be related to differences in the expression levels of the two constructs.

The predicted hBestl topology described by Hartzell et al ${ }^{44}$ shows that the amino acid mutations we have identified were probably located in either an extracellular loop or the Cterminal cytoplasmic tail. The accurate spatial location of Q293H within hBestl remains in question, because it is near the end of the last transmembrane domain and could be located in the plasma membrane, at its interface, or in the cytoplasm. Q293 is not accessible to the extracellular aqueous environment because when it is replaced with cysteine, it is apparently not modified by membrane-impermeant sulphydryl reagents. ${ }^{27}$ Q293 is the first residue in a string of 18 amino acids (293$311), 16$ of which have been shown to be linked to Best disease when mutated. These findings clearly pinpoint this as an 

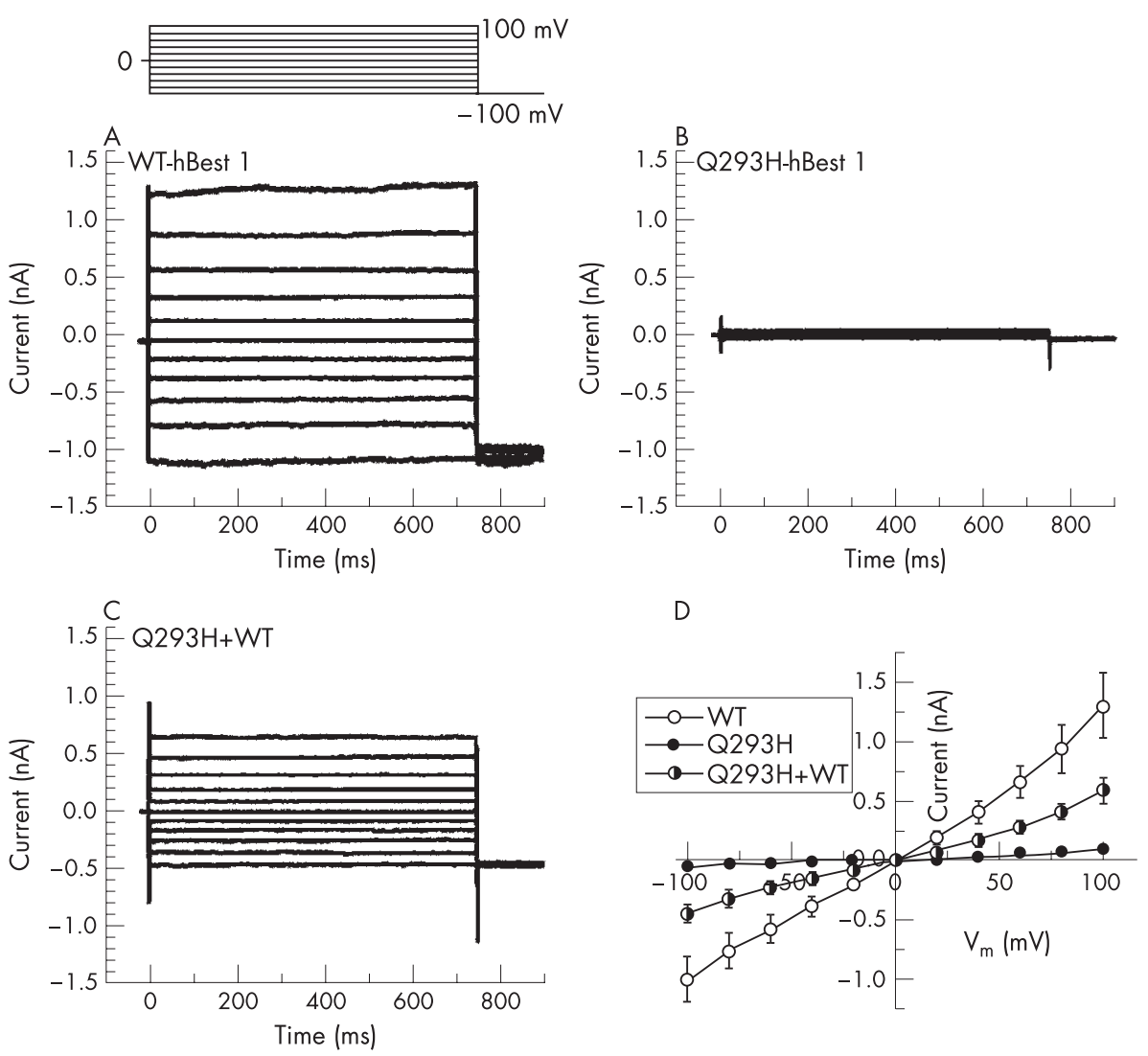

Figure 2 Whole-cell patch clamp analysis of $\mathrm{Cl}^{-}$currents induced by wild-type hBest 1 and the Q293H mutation. Q293H mutation blocked the normal function of hBestl as $\mathrm{Ca}^{2+}$-activated $\mathrm{Cl}^{-}$channel in transfected HEK-293 cells. The voltage clamp protocol is shown. $(\mathrm{A}-\mathrm{C})$ Representative current traces from cells transfected with wild-type (WT), Q293H mutant and WT+Q293H hBestl, respectively. (D) Averaged current-voltage $(I-V)$ relations for WT $(n=13), Q 293 H$ $(n=7)$ and cotransfection of WT+Q293H $(n=12)$. (E) Current amplitudes at -100 and $+100 \mathrm{mV}$ from the above recordings and those from cells transfected with EGFP alone $(n=5)$. Dots indicate data of individual cells. Whole-cell recording from transfected HEK293 cells showed that the Q293H mutant channel is non-functional when transfected alone, and considerably inhibited the wildtype current when cotransfected with WT hBestl ( $p<0.05$, two-tailed $t$ test).

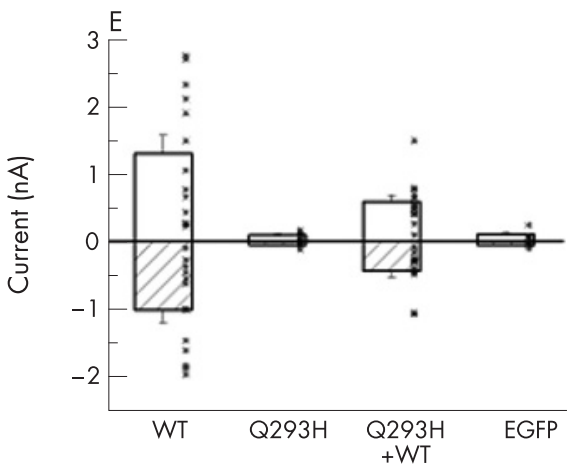

important region. Its exact function, however, remains unknown. The high concentration of acidic amino acids might make this region a candidate for a $\mathrm{Ca}^{2+}$ binding site or a protein trafficking signal, both of which often have a negative charge. Our finding that the Q293H mutant does not form functional channels in the membrane could be explained either by disruption of channel conductance or gating mechanisms or by improper trafficking of the protein to the plasma membrane.

The light peak, measured during EOG examination, reflects a depolarisation of the basal membrane of the RPE due to increased $\mathrm{Cl}^{-}$conductance. ${ }^{45}$ Several recent studies suggest that hbestl is not necessary to generate the light peak, and may regulate $\mathrm{Ca}^{2+}$ channel function. ${ }^{46}{ }^{47}$ Furthermore, they showed that voltage-dependent calcium channels (VDCCs) containing a $\beta 4$ subunit are a necessary component of the light peak pathway. Indeed, no human-inherited retinal degeneration has so far been shown to be caused by any VDCC $\beta 4$ subunit mutation. ${ }^{48}$ Moreover, patients with AVMD carrying VMD2 mutations exhibit vitelliform lesions with normal light peaks. ${ }^{49}$ Although the diminished slow light peak in the EOG is the hallmark diagnostic feature of Best disease, Marmorstein et al conclude that the diminished light peak is not the pathophysiological cause of vision loss in these individuals. Consequently, likely interactions between VDCCs and hbestl channels might contribute at least partially to explain the incomplete penetrance and the variability of mutated VMD2 expression in the asymptomatic patient (III-6) and in the patients of family $\mathrm{C}$ with symptoms of BVMD.

Our data add several more examples of amino acids that produce Best disease when mutated to different amino acids. For example, R218 was substituted with cysteine in one family and histidine in another. Furthermore, as noted above, Q293, G299 and R218 have multiple disease-associated mutations. Each of the affected families or isolated cases had a unique mutation. However, we found some mutations in several unrelated families and isolated patients. We identified the R218C mutation twice in unrelated families and isolated cases and the $\mathrm{R} 218 \mathrm{H}$ mutation four times in unrelated families and isolated cases. If we include the data from our previous studies, $^{33}{ }^{39}$ the most commonly affected amino acid residue 
in the French families and isolated patients affected by Best disease is R218 (eight alleles). Indeed, the R218C and R218H mutations were the most common and may correspond to a founder effect in the French population and other western populations. The other commonly altered amino acid residues may be mutation hotspots and/or functionally important protein residues. The fact that the same codon is the target of various missense mutations points to a key role for the corresponding amino acid residue in the proper function of the bestrophin. In conclusion, we would emphasise the importance of the genotype-phenotype correlations for the adequate evaluation of the severity of any given bestrophin mutation. The Q293H mutation illustrates this point clearly, and shows the importance of the results provided by OCT, mfERG and patch clamp analysis.

The detection rate for mutations in VMD2 is high in patients with Best disease irrespective of the method used for the genetic analysis (direct DNA sequencing, single-stranded conformational polymorphism, denaturing HPLC). This observation was confirmed in our study by the detection of one mutation for each patient with BVMD.

\section{ACKNOWLEDGEMENTS}

We thank all the patients for their cooperation in this study. This work was supported by Association Retina France (MA), AP-HP (RF), the $\mathrm{NIH}(\mathrm{HCH})$ and the American Health Assistance Foundation (HCH). We also thank Françoise Georges (President of Retina France), Professor Jean-François DHAINAUT (President of the University René DESCARTES) and Professor Patrick Berche (Dean of Paris V Medical School) for their continuous support.

\section{Authors' affiliations}

D Marchant, K Bigot, A Germain, C Marsac, M Menasche, M Abitbol, Centre de recherche thérapeutique en ophtalmologie, équipe d'accueil 2502 MENRT, Université René Descartes Paris V, Faculté de Médecine Necker-Enfants Malades, 156 rue de Vaugirard, Paris, France

O Roche, D Schmidt, P Le Neindre, J L Dufier, Département

d'ophtalmologie, Centre Hospitalier Universitaire Necker-Enfants Malades, Paris, France

D F Schorderet, IRO - Institut de Recherche en Ophtalmologie, Université de Lausanne et EPFL - Ecole polytechnique fédérale de Lausanne, Lausanne, Switzerland

K Yu, C Hartzell, Department of Cell Biology, The Center for Neurodegenerative Disease, Emory University School of Medicine, Atlanta, Georgia, USA

R Fischmeister, INSERM U769, Châtenay-Malabry, France

D Bonneau, Département de Génétique, Centre Hospitalier Universitaire d'Angers, Angers, France

V Drouin-Garraud, Département de Génétique, Centre Hospitalier Universitaire de Roven, Rouen, France

F Munier, Service d'Ophtalmologie, Hôpital Jules Gonin, Lausanne, Switzerland

Competing interests: None declared.>

\section{REFERENCES}

1 Krill AE, Morse PA, Potts AM, Klien BA. Hereditary vitelliruptive macular degeneration. Am J Ophthalmol 1966;61:1405-15.

2 Ponjavic V, Eksandh L, Andreasson S, Sjostrom K, Bakall B, Ingrast S, Wadelius C, Ehinger B. Clinical expression of Best's vitelliform macular dystrophy in Swedish families with mutations in the bestrophin gene. Ophthalmic Genet 1999;20:251-7.

3 Seddon JM, Sharma S, Chong S, Hutchinson A, Allikmets R, Adelman RA. Phenotype and genotype correlations in two best families. Ophthalmology 2003; 1 10:1724-31.

4 Yanoff M, Fine BS. Ocular pathology, 5th edn. St Louis: Mosby, 2002.

5 Mullins RF, Oh KT, Heffron E, Hageman GS, Stone EM. Late development of vitelliform lesions and flecks in a patient with best disease: clinicopathologic correlation. Arch Ophthalmol 2005; 123:1588-94.

6 Renner $\mathbf{A B}$, Tillack $\mathrm{H}$, Kraus $\mathrm{H}$, et al. Late onset is common in best macular dystrophy associated with VMD2 gene mutations. Ophthalmology 2005;112:586-92.
7 Wabbels B, Preising MN, Kretschmann U, et al. Genotype-phenotype correlation and longitudinal course in ten families with Best vitelliform macular dystrophy. Graefes Arch Clin Exp Ophthalmol 2006;244:1453-66.

8 Godel V, Chaine G, Regenbogen L, Coscas G. Best's vitelliform macular dystrophy. Acta Ophthalmol Suppl 1986;175:1-31.

9 Mohler CW, Fine SL. Long-term evaluation of patients with Best's vitelliform dystrophy. Ophthalmology 1981;88:688-92.

10 Andrade RE, Farah ME, Costa RA. Photodynamic therapy with verteporfin for subfoveal choroidal neovascularization in best disease. Am J Ophthalmol 2003;136:1179-81.

11 Noble KG, Scher BM, Carr RE. Polymorphous presentations in vitelliform macular dystrophy: subretinal neovascularisation and central choroidal atrophy. Br J Ophthalmol 1978:62:561-70.

12 Benson WE, Kolker AE, Enoch JM, Van Loo JA Jr, Honda Y. Best's vitelliform macular dystrophy. Am J Ophthalmol 1975;79:59-66.

13 Miller SA, Bresnick GH, Chandra SR. Choroidal neovascular membrane in Best's vitelliform macular dystrophy. Am J Ophthalmol 1976;82:252-5.

14 Fishman GA, Trimble S, Rabb MF, Fishman M. Pseudovitelliform macula degeneration. Arch Ophthalmol 1977;95:73-6.

15 Gass JD, Jallow S, Davis B. Adult vitelliform macular detachment occurring in patients with basal laminar drusen. Am J Ophthalmol 1985;99:445-59.

16 Felbor $\mathrm{U}$, Schilling $\mathrm{H}$, Weber $\mathrm{BH}$. Adult vitelliform macular dystrophy is frequently associated with mutations in the peripherin/RDS gene. Hum Mutat 1997; 10:301-9.

17 Deutman AF. Electro-oculography in families with vitelliform dystrophy of the fovea. Detection of the carrier state. Arch Ophthalmol 1969:81:305-16.

18 Cross HE, Bard L. Electro-oculography in Best's macular dystrophy. Am J Ophthalmol 1974;77:46-50.

19 Pollack K, Kreuz FR, Pillunat LE. Best's disease with normal EOG. Case report of familial macular dystrophy. Ophthalmologe 2005;102:891-4.

20 Palmowski AM, Allgayer R, Heinemann-Vernaleken B, Scherer V, Ruprecht KW. Detection of retinal dysfunction in vitelliform macular dystrophy using the multifocal ERG (MF-ERG). Doc Ophthalmol 2003;106:145-52.

21 Scholl HP, Schuster AM, Vonthein R, Zrenner E. Mapping of retinal function in Best macular dystrophy using multifocal electroretinography. Vision Res 2002;42:1053-61

22 Marmorstein AD, Marmorstein LY, Rayborn M, Wang X, Hollyfield JG Petrukhin K. Bestrophin, the product of the Best vitelliform macular dystrophy gene (VMD2), localizes to the basolateral plasma membrane of the retinal pigment epithelium. Proc Natl Acad Sci U S A 2000;97:12758-63.

23 Marquardt A, Stohr H, Passmore LA, Kramer F, Rivera A, Weber BH. Mutation in a novel gene, VMD2, encoding a protein of unknown properties cause juvenile-onset vitelliform macular dystrophy (Best's disease). Hum Mol Genet 1998;7:1517-25.

24 Petrukhin K, Koisti MJ, Bakall B, Li W, Xie G, Marknell T, Sandgren O, Forsman K, Holmgren G, Andreasson S, Vujic M, Bergen AA, McGarty-Dugan V, Figueroa D, Austin CP, Metzker ML, Caskey CT, Wadelius C. Identification of the gene responsible for Best macular dystrophy. Nat Genet 1998:19:241-7.

25 Stohr H, Marquardt A, Nanda I, Schmid M, Weber BH. Three novel human VMD2-like genes are members of the evolutionary highly conserved RFP-TM family. Eur J Hum Genet 2002;10:281-4.

26 Sun $\mathrm{H}$, Tsunenari T, Yau KW, Nathans J. The vitelliform macular dystrophy protein defines a new family of chloride channels. Proc Natl Acad Sci U S A 2002;99:4008-13

27 Tsunenari T, Sun H, Williams J, Cahill H, Smallwood P, Yau KW, Nathans J. Structure-function analysis of the bestrophin family of anion channels. J Biol Chem 2003;278:41114-25.

28 Qu Z, Wei RW, Mann W, Hartzell HC. Two bestrophins cloned from Xenopus laevis oocytes express $\mathrm{Ca}^{-}$activated $\mathrm{Cl}^{-}$) currents. J Biol Chem 2003:278:49563-72.

29 Seddon JM, Afshari MA, Sharma S, Bernstein PS, Chong S, Hutchinson A Petrukhin K, Allikmets R. Assessment of mutations in the Best macular dystrophy (VMD2) gene in patients with adult-onset foveomacular vitelliform dystrophy, age-related maculopathy, and bull's-eye maculopathy. Ophthalmology $2001 ; 108: 2060-7$.

30 Allikmets R, Seddon JM, Bernstein PS, Hutchinson A, Atkinson A, Sharma S, Gerrard B, Li W, Metzker ML, Wadelius C, Caskey CT, Dean M, Petrukhin K. Evaluation of the Best disease gene in patients with age-related macular degeneration and other maculopathies. Hum Genet 1999;104:449-53.

31 Kramer F, White K, Pauleikhoff D, Gehrig A, Passmore L, Rivera A, Rudolph G, Kellner U, Andrassi M, Lorenz B, Rohrschneider K, Blankenagel A, Jurklies B, Schilling H, Schutt F, Holz FG, Weber BH. Mutations in the VMD2 gene are associated with juvenile-onset vitelliform macular dystrophy (Best disease) and adult vitelliform macular dystrophy but not age-related macular degeneration. Eur J Hum Genet 2000;8:286-92.

32 White K, Marquardt A, Weber BH. VMD2 mutations in vitelliform macular dystrophy (Best disease) and other maculopathies. Hum Mutat 2000;15:301-8.

33 Marchant D, Gogat K, Boutboul S, Pequignot M, Sternberg C, Dureau P, Roche O, Uteza Y, Hache JC, Puech B, Puech V, Dumur V, Mouillon M, Munier FL, Schorderet DF, Marsac C, Dufier JL, Abitbol M. Identification of novel VMD2 gene mutations in patients with best vitelliform macular dystrophy. Hum Mutat 2001;17:235.

34 Qu Z, Fischmeister R, Hartzell C. Mouse bestrophin-2 is a bona fide $\mathrm{Cl}^{-}$) channel: identification of a residue important in anion binding and conduction. $J$ Gen Physiol 2004; 123:327-40.

35 Bakall B, Marknell T, Ingvast S, Koisti MJ, Sandgren O, Li W, Bergen AA Andreasson S, Rosenberg T, Petrukhin K, Wadelius $C$. The mutation spectrum of the bestrophin protein--functional implications. Hum Genet 1999;104:383-9. 
36 Caldwell GM, Kakuk LE, Griesinger IB, Simpson SA, Nowak NJ, Small KW Maumenee IH, Rosenfeld PJ, Sieving PA, Shows TB, Ayyagari R. Bestrophin gene mutations in patients with Best vitelliform macular dystrophy. Genomics 1999;58:98-101.

37 Kramer F, Mohr N, Kellner U, Rudolph G, Weber BH. Ten novel mutations in VMD2 associated with Best macular dystrophy (BMD). Hum Mutat 2003;22:418.

38 Lotery AJ, Munier FL, Fishman GA, Weleber RG, Jacobson SG, Affatigato LM, Nichols BE, Schorderet DF, Sheffield VC, Stone EM. Allelic variation in the VMD2 gene in best disease and age-related macular degeneration. Invest Ophthalmol Vis Sci 2000;41:1291-6.

39 Marchant D, Gogat K, Dureau P, Sainton K, Sternberg C, Gadin S, Dollfus H, Brasseur G, Hache JC, Dumur V, Puech V, Munier F, Schorderet DF, Marsac C, Menasche M, Dufier JL, Abitbol M. Use of denaturing HPLC and automated sequencing to screen the VMD2 gene for mutations associated with Best's vitelliform macular dystrophy. Ophthalmic Genet 2002;23:167-74.

40 McGee TL, Devoto M, OHt J, Berson EL, Dryja TP. Evidence that the penetrance of mutations at the RP1 1 locus causing dominant retinitis pigmentosa is influenced by a gene linked to the homologous RP1 1 allele. Am J Hum Genet 1997;61:1059-66.

41 Esumi N, Oshima Y, Li Y, Campochiaro PA, Zack DJ. Analysis of the VMD2 promoter and implication of E-box binding factors in its regulation. J Biol Chem 2004;279: 19064-73.

42 Vithana EN, Abu-Safieh L, Allen MJ, Carey A, Papaioannou M, Chakarova C, Al-Maghtheh M, Ebenezer ND, Willis C, Moore AT, Bird AC, Hunt DM,
Bhattacharya SS. A human homolog of yeast pre-mRNA splicing gene, PRP31, underlies autosomal dominant retinitis pigmentosa on chromosome 19q13.4 (RP1 1). Mol Cell 2001;8:375-81.

43 Qu Z, Hartzell C. Determinants of anion permeation in the second transmembrane domain of the mouse bestrophin-2 chloride channel. J Gen Physiol 2004;124:371-82.

44 Hartzell C, Qu Z, Putzier I, Artinian L, Chien LT, Cui Y. Looking chloride channels straight in the eye: bestrophins, lipofuscinosis, and retinal degeneration. Physiology (Bethesda) 2005;20:292-302.

45 Linsenmeier RA, Steinberg RH. A light-evoked interaction of apical and basal membranes of retinal pigment epithelium: c-wave and light peak. J Neurophysiol 1983;50:136-47.

46 Rosenthal R, Bakall B, Kinnick T, Peachey N, Wimmers S, Wadelius C, Marmorstein A, Strauss O. Expression of bestrophin-1, the product of the VMD2 gene, modulates voltage-dependent $\mathrm{Ca} 2+$ channels in retinal pigment epithelial cells. Faseb J 2006;20:178-80.

47 Marmorstein LY, Wu J, McLaughlin P, et al. The light peak of the electroretinogram is dependent on voltage-gated calcium channels and antagonized by bestrophin (best-1). J Gen Physiol 2006;127:577-89.

48 Escayg A, De Waard M, Lee DD, et al. Coding and noncoding variation of the human calcium-channel beta4-subunit gene CACNB4 in patients with idiopathic generalized epilepsy and episodic ataxia. Am J Hum Genet 2000;66:1531-9.

49 Epstein GA, Rabb MF. Adult vitelliform macular degeneration: diagnosis and natural history. Br J Ophthalmol 1980;64:733-40. 